SQUiBS

\title{
A Valoração de Traços de Concordância dentro do DP *
}

\author{
(Concord Features Valuing within DP)
}

\author{
Telma M.V. MagalHães \\ (Universidade Estadual de Campinas/FAPESP)
}

ABSTRACT: This paper argues in favor of a concord features valuing within the DP in terms of the Agree operation (Chomsky, 1999), with no recourse to any other mechanism. I show that Agree accounts for feature valuing both in the sentence level as well as in the DP, contrary to Chomsky's (1999) suggestion that concord in DP should involve some other checking mechanism.

KEY-WORDS: Valuing; Feature matching; Concord; Probe; Goal; Interpretable features; Uninterpretable features.

Resumo: Este trabalho argumenta em favor da valoração dos traços de concordância dentro do DP em termos da operação Agree (Chomsky, 1999) sem a necessidade de estipular nenhum outro mecanismo para tanto. Mostro que Agree dá conta da valoração de traços tanto no nível da sentença quanto no nível do DP, contra a sugestão de Chomsky (1999) de que concordância no DP envolveria algum outro mecanismo de checagem.

PaLAVRAS-CHAVE: Valoração; Combinaçãa de traços; Concordância; Sonda; Alvo; Traços interpretáveis; Traços não-interpretáveis.

\footnotetext{
* Esse artigo é resultado do meu trabalho apresentado como qualificação na área de Gramática defendida junto ao Instituto de Estudos da Linguagem da Universidade Estadual de Campinas. Agradeço ao Professor Jairo Nunes por sua orientação, comentários e sugestões durante as várias fases por que passou este trabalho. Gostaria também de agradecer aos Professores Mary Kato, Ruth Lopes e Zeljko Boskovic por seus comentários e sugestões. Versões anteriores deste trabalho foram apresentadas no Curso Seminário Avançado em Gramática na UNICAMP, no $50^{\circ}$ GEL (USP), no Workshop Pesquisas em Morfossintaxe: Perspectivas Históricas e Minimalistas (UNICAMP) e no XIX Gelne (UFC). Gostaria de agradecer a todos os participantes destes eventos as contribuições dadas. Desnecessário dizer que as falhas ainda existentes são de minha inteira responsabilidade. Durante a elaboração deste trabalho, contei com o apoio financeiro da FAPESP, processo 00/14378-5.
}

D.E.L.T.A., 20:1, $2004(149-170)$ 


\section{Introdução}

Chomsky (1999) sugere que há dois mecanismos de concordância: um no nível da sentença e outro dentro do DP, que ele, em nota, chama de concord (cf. nota 7, p-36). No nível da sentença, a checagem de traços é realizada através de Agree, já dentro do DP, segundo Chomsky (1999), essa mesma checagem envolveria unicamente concatenação (Merge). Neste trabalho, mostro que é possível realizar a checagem de traços de concordância dentro do DP usando o sistema Agree como apresentado em Chomsky (1999) e, que, portanto, não há necessidade de postular uma nova relação de checagem para dar conta da concordância dentro do DP. Para tal proposta, estou me baseando no sistema de valoração de traços formais de construções participiais proposta por Chomsky (1999).

O trabalho está organizado da seguinte forma: na seção 1, faço um resumo do sistema de checagem proposto em Chomsky (1995-2001); na seção 2, esboço rapidamente a questão da concordância dentro de DP e a hipótese que estou assumindo para a realização da checagem de seus traços; a seção 3 traz a proposta de Chomsky (1999) para a valoração de traços em construções participiais; Na seção 4, faço uma breve discussão a respeito dos traços não-interpretáveis e interpretáveis no DP; na seção 5 , apresento minha proposta de análise.

\section{Um Breve Resumo da Teoria de Checagem: Chomsky (1995-2001)}

De acordo com Chomsky (1995-2001) um item lexical possui traços formais interpretáveis e não-interpretáveis. Entre os traços interpretáveis encontram-se os traços- $\phi$ dos nomes. O Caso estrutural de nomes e os traços- $\phi$ de categorias que concordam com os nomes são não-interpretáveis. Na computação para LF, os traços formais não-interpretáveis precisam ser checados (eliminados) para que a derivação convirja nesse nível. Os traços interpretáveis, por sua vez, não precisam ser checados porque eles são lidos por LF sem problemas.

Na teoria de checagem de Chomsky 1995, a checagem dos traços se dá via movimento de traços, que são atraídos por um alvo que tem traços não-interpretáveis. O traço D-forte de T (alvo), por exemplo, desencadeia 
o movimento do sujeito até seu Spec para satisfazer o EPP. T, então, tem seu traço $\mathrm{D}$ checado e apagado e o sujeito também tem seu traço de Caso checado por $T$. Os traços- $\phi$ do sujeito serão checados quando o verbo for elevado e adjungido a T. Então, o sujeito checa e apaga os traços- $\phi$ do verbo. O traço de Caso do sujeito, por ser não-interpretável, é apagado quando checado, mas os seus traços- $\phi$ permanecem mesmo depois da checagem porque são interpretáveis, como ilustrado em (1):

(1)

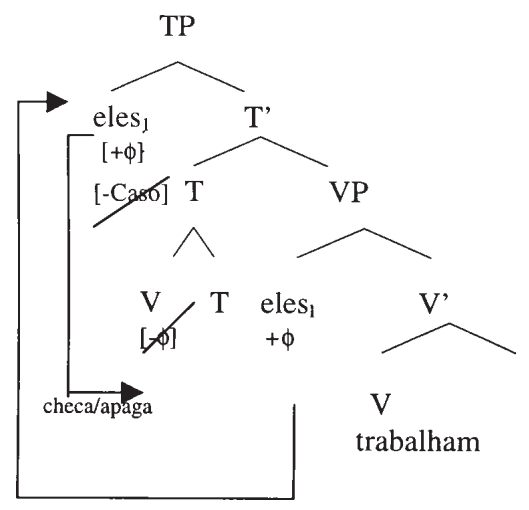

Chomsky (1998) propõe que não há nenhum traço se movendo no componente coberto. As relações de checagem se dão todas abertamente mediante uma operação chamada Agree que se estabelece entre dois elementos: uma sonda (probe) e um alvo (goal). No caso de uma relação-A, por exemplo, a sonda tem traços- $\phi$ não-interpretáveis e procura os traços- $\phi$ interpretáveis do alvo. O alvo, por sua vez, tem de ter um traço de Caso estrutural não checado que o deixa ativo para participar de relações de checagem com a sonda ${ }^{1}$. No momento da combinação (matching) dos traços- $\phi$ entre sonda e alvo, Agree apaga os traços não-interpretáveis somente se a sonda e o alvo estão apropriadamente relacionados (o alvo deve estar na posição de complemento da sonda), são $\operatorname{completos}^{2}$ (com um conjunto pleno de traços) e se o alvo estiver ativo, isto é, com um traço não-interpretável para ser checado, como em (2):

1 Se não for relação-A, o alvo precisa ter algum outro traço não-interpretável que o deixe ativo para a checagem.

2 Se incompletos, somente os traços não-interpretáveis da sonda são apagados. 
(2)

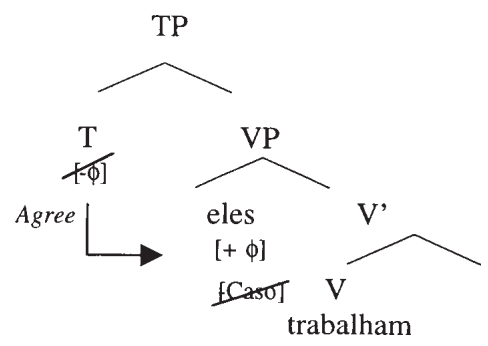

Em (2) a sonda ( $\mathrm{T}$ ) possui traços- $\phi$ não-interpretáveis. O alvo (eles) possui traços- $\phi$ interpretáveis e um traço de Caso estrutural (trata-se de uma relação-A) não checado que permite que o alvo possa entrar em relação de checagem com a sonda. A sonda e o alvo se combinam, os traços- $\phi$ não-interpretáveis da sonda são checados e apagados e o traço de Caso estrutural do alvo também é checado e apagado.

Em Chomsky (1999) é proposto que a interpretabilidade dos traços é determinada no léxico, pela GU, e a distinção entre os traços é estabelecida em termos de valor: Os traços não-interpretáveis entram na derivação sem valor e os traços interpretáveis entram na derivação com seus valores especificados. Por exemplo, os traços de número (n), gênero (g) do nome entram dessa forma na derivação[n:pl / g:f), já os traços dos adjetivos entram $\operatorname{assim}[\mathrm{n}: / \mathrm{g}:]^{3},{ }^{4}$.

Os valores dos traços não-interpretáveis são determinados por Agree, que funciona da seguinte forma: a sonda, que tem traços- $\phi$ não-interpretáveis, se combina com um alvo, que tem traços- $\phi$ interpretáveis e também um traço de Caso subespecificado 5 . No momento em que a sonda e o

3 Considerando-se que para Chomsky traços de gênero e número são interpretáveis no nome, para as outras categorias esses traços são não-interpretáveis.

4 Lista de abreviaturas a serem usadas neste trabalho: g: gênero; n: número; p: pessoa; PRT: particípio; OD: objeto direto (argumento interno); pl: plural; sg: singular; m: masculino; gen: genitivo. Quando eu estiver me referindo a traços valorados, as abreviaturas serão precedidas pelo sinal + e quando os traços forem não-valorados as abreviaturas serão precedidas pelo sinal -. Com relação ao traço de Caso, quando ele ainda não tiver sido valorado terá a seguinte notação [-Caso], depois de valorado receberá a abreviatura correspondente ao valor que ele recebeu: nom: nominativo; ac: acusativo.

5 Vale lembrar que no sistema de checagem de 1999, Caso é um traço subespecificado, ou seja, o alvo tem um traço de Caso que só será especificado de acordo com a categoria funcional com a qual ele concordar. Se for T, o Caso será nominativo, se for v será acusativo. 
alvo se combinam, os traços- $\phi$ não-interpretáveis da sonda e o Caso do alvo são valorados. Assim, por exemplo, no caso da concordância entre sujeito e verbo, os traços- $\phi$ de $T$ (sonda), que são não-interpretáveis se combinam com traços- $\phi$ interpretáveis do sujeito (alvo), a operação Agree valora os traços não-interpretáveis de $\mathrm{T}$, bem como valora o traço de Caso do sujeito que, em virtude da sua concordância com a categoria funcional T, será nominativo, conforme ilustrado em (3b).

(3)

a.
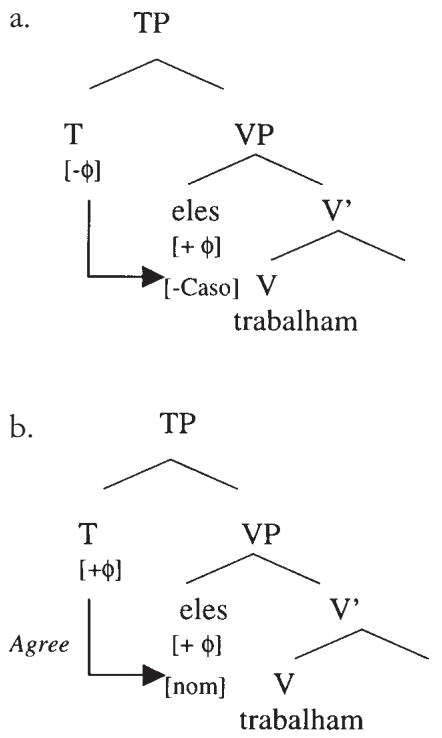

No nível da fase forte (CP ou vP) Spell-Out é aplicado ${ }^{6}$. Os traços não-interpretáveis e o Caso com seus valores já assinalados são removidos da computação para permitir convergência em LF e o objeto sintático é mandado para a fonologia (cf. Chomsky 1999: 10).

\footnotetext{
${ }^{6}$ Para a minha análise é crucial que Spell-Out seja aplicado só no CP ou vP, porque dessa forma os traços- $\phi$ do DP, mesmo depois de serem valorados, continuarão ativos para que o DP possa entrar numa relação de Agree com uma sonda e valore seu traço de Caso. Considerando que para Chomsky (1999) os traços que são valorados só serão apagados no nível da fase forte (vP ou CP) quando Spell-Out for aplicado e o objeto sintático for mandado para o componente fonológico.
} 


\section{Concordância dentro de DP}

Além da relação concordância sujeito/verbo, ou objeto/verbo, tratadas por Chomsky, existem também relações de concordância que envolvem modificadores, determinantes e o Nome dentro de DPs e, nesses casos, a concordância aparece sobre os modificadores e determinantes e, aparentemente, é controlada pelos traços do nome:

(4) a. As casas brancas. (Português)

b. Las casas blancas. (Espanhol)

'As casas brancas'

c. Le mie case belle (Italiano)

'As minhas casas belas'

O ponto aqui é: (i) Se os traços- $\phi$ somente são interpretáveis nos no$\mathrm{mes}^{7}$ como afirma Chomsky (1995-2001), os modificadores e determinantes dentro de DPs contêm traços- $\phi$ não-interpretáveis que necessitam ser checados para que a derivação convirja em LF. Logo, a questão que se coloca é: (ii) como realizar a checagem de traços não-interpretáveis dos modificadores e determinantes dentro de um DP utilizando a operação de checagem Agree de Chomsky (1998-2001).

Carstens (2000), baseando-se na operação Agree de Chomsky (1998), tenta realizar a checagem dos traços do DP [le mie case bele] do italiano, como em (5a), propondo o seguinte: o determinante /le/, o possessivo /mie/ e o adjetivo /belle/ têm traços não-interpretáveis e, talvez, pudessem ser construídos como sondas, tomando $\mathrm{N}$ como alvo, conforme $(5 \mathrm{~b})^{8}$ :

\footnotetext{
É discutível se os traços de número são mesmo interpretáveis no nome ou se seriam interpretáveis no determinante (Abney, 1987; Olsen, 1989; Longobardi, 1994). Discutirei isso na seção 4 . O importante é que, seja como for, existem traços não-interpretáveis no DP que precisam ser checados para que a derivação possa convergir.

8 Carstens (2000) não faz nenhuma observação em seu trabalho, com relação ao efeito de minimalidade que deveria ser produzido pelo adjetivo para a combinação sonda (D) e alvo (N).
} 
(5) a. Le mie case belle.

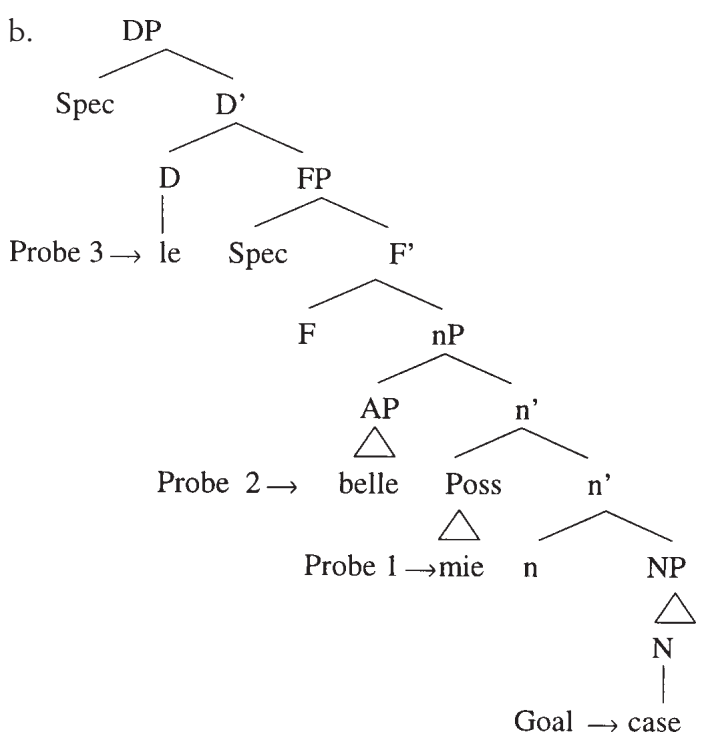

Carstens (2000) afirma que o requerimento de que o alvo tem de ter Caso é encontrado, bastando para tanto supormos que o Caso acusativo ou nominativo de um DP é uma propriedade morfológica do seu núcleo $\mathrm{N}^{9}$. Assim sendo, Agree é aplicado ciclicamente como em (5b): primeiro entre Poss e N; em seguida entre $\mathrm{A}(\mathrm{P})$ e N; e finalmente entre D e N. Segundo Carstens (2000), o Caso de $\mathrm{N}$ deveria ser apagado, de acordo com o sistema de Chomsky (1998), quando Agree se aplica. Entretanto, Carstens (2000) afirma que o apagamento do Caso de $\mathrm{N}$ não é possível, se considerarmos que $\mathrm{N}$ serve como alvo interativamente dentro do DP, e que, posteriormente, o DP terá que servir de alvo para $\mathrm{v}$ ou $\mathrm{T}$, pois uma vez que o traço de Caso de $\mathrm{N}$ foi apagado, $\mathrm{N}$ se torna inativo para entrar em novas relações de checagem e, portanto, o DP não poderia servir de alvo para a

\footnotetext{
9 A suposição comum de que Caso nominativo ou acusativo é uma propriedade morfológica do nome não é tão óbvia quando se consideram línguas como o Alemão. Segundo Olsen (1989), em Alemão Moderno, os nomes são flexionalmente empobrecidos. Eles apresentam distinção flexional entre singular e plural, mas não manifestam finais flexionais visíveis nem para gênero, nem para Caso. Já os determinantes apresentam distinções morfológicas ricas para g, n e Caso, características das formas pronominais da língua. Por isso, ela considera que os traços de Caso do Alemão estão em DET e não no nome.
} 
sonda ( $\mathrm{v}$ ou $\mathrm{T}$ ), porque lhe faltaria um traço que o deixasse ativo para a relação de checagem. Carstens (2000) assume, então, a teoria de checagem de Chomsky (1995) e propõe que os núcleos existentes dentro do DP (a saber, D, Num e $N$ ) possuem traços- $\phi$ interpretáveis que checam os traços- $\phi$ não-interpretáveis dos seus concordantes numa relação de especificador/núcleo, como ilustrado em (6):

(6)

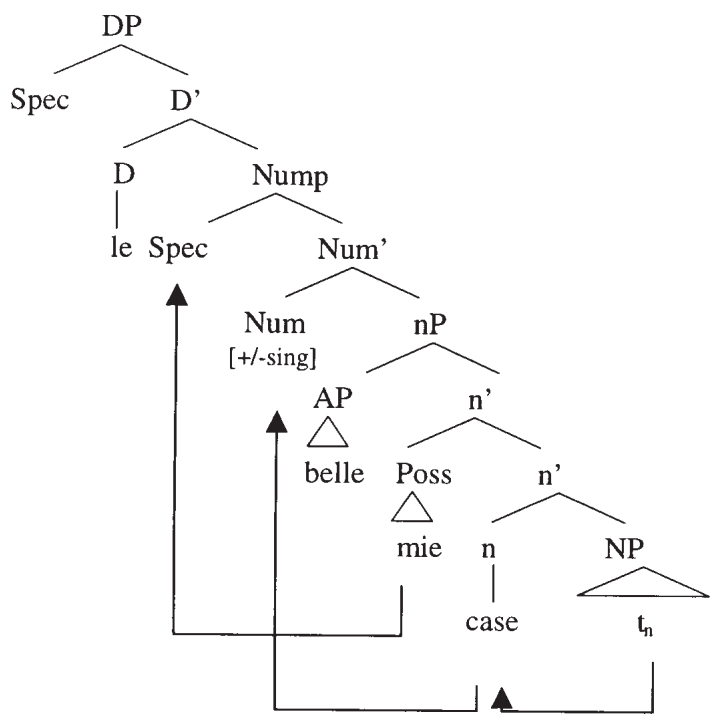

No caso do determinante /le/ Carstens propõe que ocorre um movimento em LF dos traços formais de $\left[_{\mathrm{Num}} \mathrm{Num}+\mathrm{N}\right]$ para o Spec de D para a checagem dos traços de gênero e número não-interpretáveis de $\mathrm{D}$.

A minha proposta é que a checagem de traços não-interpretáveis dentro de DPs pode ser realizada, se assumirmos o sistema Agree de Chomsky com as adaptações apresentadas nos textos de 1999 e 2001. Assumirei como hipótese que a valoração dos traços formais do DP se dá da seguinte maneira: primeiro, os traços- $\phi$ dos concordantes são valorados entre eles e em seguida, o DP tem seu Caso valorado por uma sonda. Esta hipótese está baseada na proposta que Chomsky (1999) apresenta para a valoração de traços em construções participiais, que será mostrada na seção a seguir. 


\section{Valorando os traços em construções participiais (Chomsky 1999)}

Chomsky (1999) afirma que em construções de passivas participiais como representado em (7) temos casos de tripla concordância: em (7a) T deleta os traços não-interpretáveis do EXPL (induz alçamento) e atribui Nominativo para $\underline{\mathrm{OD}}$; em (7b) $\underline{\mathrm{v}}$ deleta os traços não-interpretáveis do EXPL (mas sem alçamento para Spec, $\underline{\text { v }}$ ) e atribui acusativo para OD. Além dessas duas concordâncias, há também concordância do particípio (PRT) com o objeto direto (OD).

(7) (a) $[C[\mathrm{~T}$ seem

[EXPL to have been [ ${ }_{\alpha}^{P R T}$ caught [ ${ }_{\text {OD }}$ several fish $\left.\left.\left.\left.]\right]\right]\right]\right]$

(b) $\sum_{\beta} \underline{v}$ expect

Chomsky (1999) propõe, então, que a valoração dos traços em construções como (7) é realizada em duas etapas: uma etapa $\alpha$ em que PRT tem seus traços- $\phi$ valorados pelo objeto direto (OD); e uma etapa $\beta$ em que o Caso de PRT e o do OD são valorados pela sonda. Considerando a etapa $\alpha$ em (8), vejamos como funciona essa proposta.

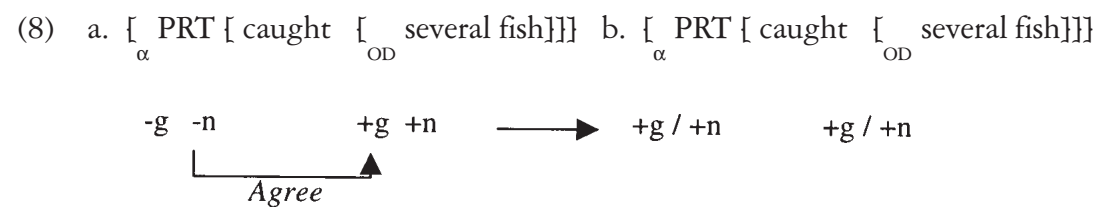

Em (8a) o particípio (PRT) tem traços- $\phi$ não-interpretáveis, sem valor, e recebe os valores do OD sob Agree (8b). Segundo Chomsky, se PRT tivesse seus traços- $\phi$ apagados quando valorados, ele ficaria invisível para a combinação com a sonda, não poderia ter seu Caso valorado na próxima etapa e a derivação fracassaria ${ }^{10}$. Para que os traços não-interpretáveis mesmo valorados ainda possam permanecer visíveis para que PRT possa ter seu

10 Lembrando aqui que o que deixa um elemento ativo para entrar em relação de concordância são os seus traços não-interpretáveis, Caso é valorado como conseqüência da combinação de traços- $\phi$ entre uma sonda e um alvo. (cf.: Chomsky,1999: 5). 
Caso valorado, Chomsky (1999) vai assumir que os traços valorados só serão apagados no nível da fase forte (vP ou CP) quando Spell-Out for aplicado e o objeto sintático for mandado para o componente fonológico. Como SpellOut ainda não aconteceu, os traços- $\phi$ de PRT em (8b), mesmo valorados, permanecem visíveis para a etapa $\beta$ do ciclo, onde o Caso será valorado.

Na próxima etapa ( $\beta$ ), que está representada em (9), a sonda (T) se combina com o expletivo e deleta o traço não-interpretável de pessoa do expletivo; em seguida, a sonda ( $\mathrm{T}$ ) se combina com o alvo (PRT), valorando o traço de Caso de PRT e depois ela se combina com o alvo (OD) valorando o traço de Caso de OD, bem como traços- $\phi$ da própria sonda $(\mathrm{T})$ (uma vez que OD tem um conjunto completo de traços- $\phi$ ):

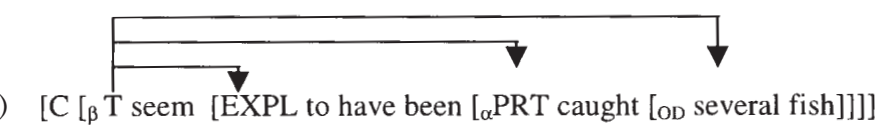

Segundo Chomsky (1999) não há nenhum efeito de minimalidade produzido por EXPL e nem por PRT na combinação da sonda (T) com o alvo (OD) em (9), porque EXPL e PRT são defectivos, ou seja, a sonda só se combina em alguns traços com eles (a saber, os traços de pessoa para EXPL e gênero/número para $\mathrm{PRT}^{11}$ ), assim os outros traços ficam livres para procurar um alvo, o que permite que os traços de gênero/número da sonda passem por EXPL, se combinem com PRT, bem como que os traços de pessoa passem por PRT, permitindo a combinação sonda-OD. O resultado, então, é uma combinação/concordância tripla em (9): (sonda, EXPL), (sonda, PRT) e (sonda, OD). PRT e OD concordam diretamente um com o outro para gênero e número, e indiretamente para Caso estrutural, uma vez que cada um concorda com a sonda. Em (10) temos um exemplo da concordância de particípio em Lituano. ${ }^{12}$

$\begin{array}{llll}\text { (10) Nãmas } & \text { buvo } & \text { mano } & \text { pastaty-t-as } \\ \text { casa-nom } / \mathrm{m} / \mathrm{sg} & \text { foi } & \text { eu-gen } & \begin{array}{c}\text { construir-prt-nom } / \mathrm{m} / \mathrm{sg} \\ \text { 'A casa foi construída por mim' }\end{array}\end{array}$

(Nunes, 1994a: p.65)

11 PRT não tem traço de pessoa.

12 Com este exemplo quero apenas mostrar a concordância de número e gênero entre PRT e OD (argumento interno) e que PRT e OD apresentam concordância de Caso. Não me preocupei com o EXPL porque ele não é relevante para o meu trabalho. Para maiores detalhes sobre concordância de particípio em Lituano remeto o leitor a Nunes (1994a, b). 


\section{Sobre traços interpretáveis e não interpretáveis no DP}

Chomsky (1995-2001) assume que o traço de número é somente interpretável no nome e que para outros itens esse traço é não-interpretável. No entanto, evidências empíricas indicam que os traços de número estão, na verdade, localizados no determinante (DET) (cf. Abney, 1987; Olsen, 1989, Longobardi, 1994).

Abney (1987) com base em dados de línguas como Húngaro, Turco, Esquimó e Mayan providencia evidências de que o DET nessas línguas é o lugar dos traços gramaticais (número, gênero e pessoa). Por isso ele propõe que o a categoria DET no NP é semelhante ao INFL na sentença, como ilustrado em (11), podendo, portanto, selecionar um complemento lexical e projetar uma posição de especificador. O elemento AGR dentro do DP, assim como o AGR verbal, pode assinalar Caso para o seu sujeito (ou especificador) e controlar a concordância morfológica do seu complemento NP:

(11) a.

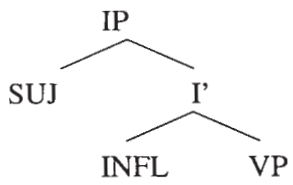

[Tempo] b.

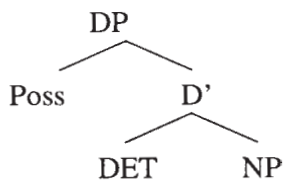

[AGR]

[AGR]

Abney (1987) propõe a estrutura (11b) para o sintagma nominal baseado no fato de que nas línguas citadas acima o núcleo nominal concorda morfologicamente com os possessivos de seus sintagmas em pessoa e número do mesmo modo que um verbo concorda com o seu sujeito nesses traços. Um dos dados apresentados por ele é do Húngaro que está ilustrado em (12):

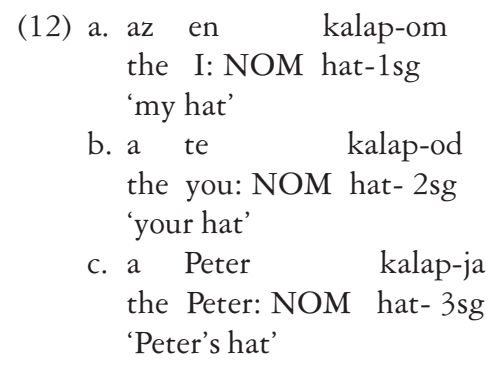

(Abney, 1987: p. 18) 
Kalap 'chapéu', em (12), concorda com seu possuidor em número e pessoa. O possuidor, por sua vez, possui Caso nominativo como ocorre com o sujeito da sentença.

Baseando-se na proposta de Abney (1987), Olsen (1989) propõe que em alemão a categoria funcional DET também possui um AGR com valores explícitos para os traços- $\phi$ do DP. Esses traços são expressos na forma de um afixo fonológico (representado pelas letras maiúsculas em 13) quando AGR é especificado como terceira pessoa, porque somente os pronomes pessoais são especificados para $1^{\mathrm{a}}$. e $2^{\mathrm{a}}$. pessoas:

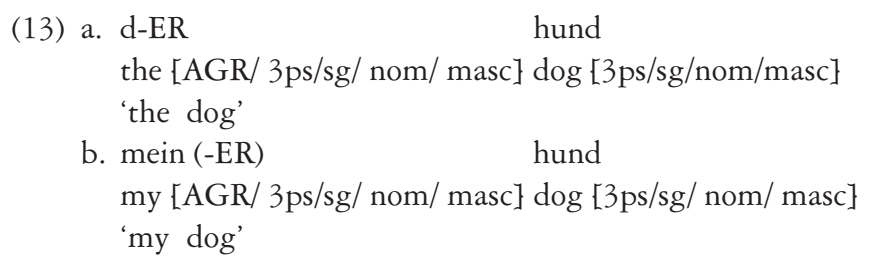

(Olsen, 1989: p. 41)

Segundo a autora, os traços- $\phi$ [gênero, número, pessoa e Caso] localizados em DET percolam para o NP produzindo a relação de concordância entre DET e seu complemento NP.

Para a minha análise, vou assumir a estrutura de DP proposta por Abney (1987) e que, nesse sintagma, o determinante (D) possui traços de número interpretáveis ${ }^{13}$ e de gênero não interpretáveis; o nome possui traços de gênero interpretáveis e de número não-interpretáveis ${ }^{14}$. Para os outros itens dentro do DP esses traços são não-interpretáveis.

O fato de os traços de número do DP serem interpretáveis no determinante e não no nome, como afirma Chomsky (1995-2001), pode trazer alguma luz para o que acontece em alguns dialetos do Português do Brasil, onde o morfema de plural não aparece em todos itens dentro do DP, sendo realizado, muitas vezes, somente no determinante (cf: Scherre,1988; Lobato,1994), como exemplificado em 14:

13 Para evidências de que D carrega o importe semântico de número cf.: Longobardi (1994).

14 Mesmo no inglês onde o morfema de plural aparece realizado no nome, temos evidência de que os traços de número são interpretáveis em $\mathrm{D}$ nessa língua, uma vez que há instâncias de realização de plural em determinantes como em these e those. 
(14) As casa (s) bonita (s)

Como afirmou Abney (1987), existe uma relação selecional semântica no $\mathrm{DP}$ entre $\mathrm{D}$ e $\mathrm{N}$ semelhante à relação existente no IP entre o sujeito $\mathrm{e}$ o verbo. No DP, D é o núcleo que seleciona o NP como complemento do mesmo modo que o VP funciona como complemento para Infl. Temos assim, uma relação argumento/ predicado entre $\mathrm{D}$ e $\mathrm{N}$ no sintagma nominal e sujeito e verbo no sintagma verbal. Na sentença, os traços de número são interpretáveis no sujeito (argumento) e não-interpretáveis no verbo (predicado). O mesmo acontece no DP: traços de número são interpretáveis no $\mathrm{D}$ (argumento de $\mathrm{N}$ ) e não-interpretáveis em $\mathrm{N}$ (predicado).

Se pensarmos em termos de concordância entre sujeito/verbo o que temos no PB é que a flexão de número começou a desaparecer ou enfraquecer no predicado, por isso nós temos em alguns dialetos construções como $(15)^{15}$ :

(15) a. Nós vai.

b. As menina.

Em (15) os traços de número só se manifestam no argumento. Podemos pensar que a presença de traços de número no argumento está relacionada ao fato de os traços de número serem interpretáveis nos argumentos. No momento em que há uma perda da realização da flexão de número nos itens do sintagma, a realização fonológica dos traços se dá, exatamente, naquele item em que o traço é interpretável.

\section{Valorando os traços de concordância do DP}

A minha proposta é que os elementos internos a DP têm seus traços valorados da mesma maneira como é realizada a valoração de traços formais em construções participiais ${ }^{16}$, porque os itens dentro de um DP como

15 Gostaria de agradecer à Profa. Mary Kato pela sugestão.

16 Diferentemente do que propõe Chomsky (1999) para construções participiais, eu não falarei aqui em etapas por considerar que as etapas, na verdade, são uma conseqüência da análise que vou propor e não um pré-requisito para ela. O meu objetivo com isto é eliminar o uso de um mecanismo a mais o que tornaria a análise pouco elegante. 
(4), repetido aqui como (16), também concordam entre si como acontece com o PRT e o OD. Primeiramente, acontece a valoração dos traços- $\phi$ dos concordantes do DP para depois ocorrer a valoração do traço de Caso.

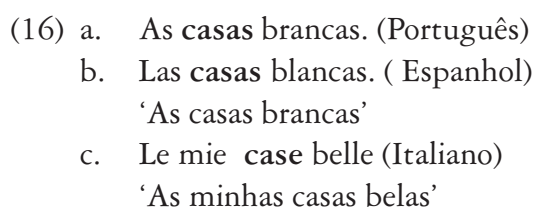

No DP, os determinantes (D) possuem traços de gênero não-valorados, isto é, não-interpretáveis e precisam se combinar com um alvo que possa valorar os seus traços de gênero. Esse alvo é o nome, que no momento da combinação com o $\mathrm{D}$ vai poder também valorar o seu traço de número:

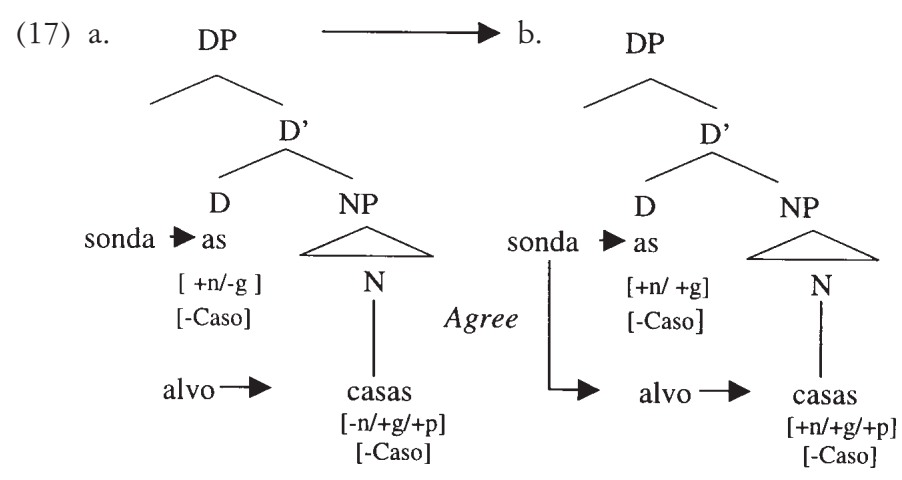

Em (17a), a sonda $D$, que tem um traço de gênero não-valorado se combina com o nome para valorar esse traço. Acontece que $\mathrm{N}$ também tem um traço não-valorado (número). No momento em que $\mathrm{D}$ e $\mathrm{N}$ se combinam, $\mathrm{D}$ valora o traço de número de $\mathrm{N}$ e ao mesmo tempo $\mathrm{N}$ valora o traço de gênero de $\mathrm{D}$, como mostrado (17b). Mas observe que o DP ainda tem um traço de Caso não-valorado (-Caso), que só vai receber um valor quando o DP entrar em relação de concordância com uma sonda $T$ ou v. Se essa sonda for T, o Caso do DP será valorado como nominativo. Se a sonda for v, o DP terá seu Caso valorado como acusativo. A representação em (18) exemplifica uma estrutura com os traços- $\phi$ de $T$ e o Caso do DP sem valor: 
(18)

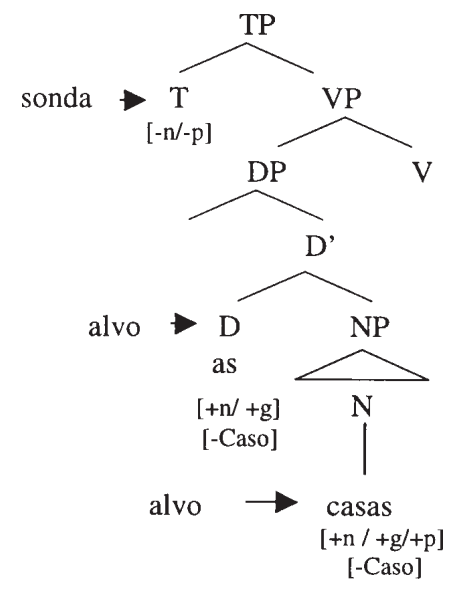

Como mostrado em (18), a sonda $T$ tem traços-f não-valorados (a saber, número e pessoa) e procura um alvo para valorar esses traços. Quando a sonda ( $\mathrm{T}$ ) encontra $\mathrm{D}$ (alvo), ela valora o seu traço de número, bem como valora o traço de Caso de $\mathrm{D}$, como representado em (19a). Mas a sonda (T) não pode valorar o seu traço de pessoa porque $\mathrm{D}$ não possui traço de pessoa. Então, a sonda continua a sua procura por um alvo e encontra $\mathrm{N}$ que possui traço de pessoa e pode valorar o traço de pessoa de T, como mostrado em (19b) ${ }^{17}$. A sonda (T), então, valora o seu traço de pessoa, bem como valora o traço de Caso de N. Por ter sido $\mathrm{T}$ a sonda com a qual os itens dentro do DP estabeleceram a relação Agree, o Caso do DP será nominativo:

17 Não há efeito de minimalidade induzido por $\mathrm{D}$ na combinação sonda $(\mathrm{T})$ e alvo $(\mathrm{N})$ para a valoração de Caso de $\mathrm{N}$, porque $\mathrm{D}$ é defectivo em traço de pessoa e, por isso, $\mathrm{T}$ pode continuar sua procura por um alvo que tenha o traço de pessoa. 
(19) a.

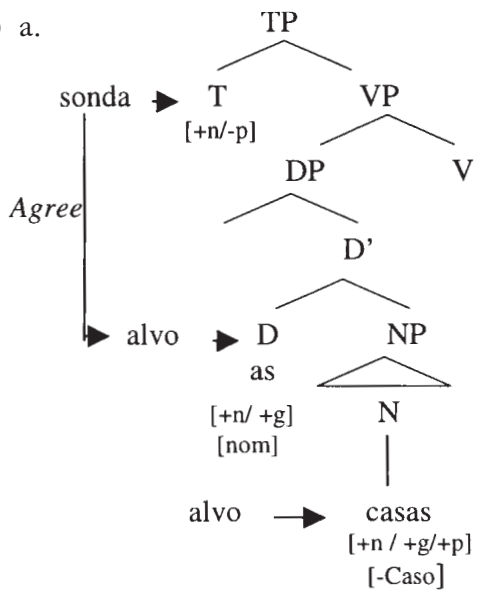

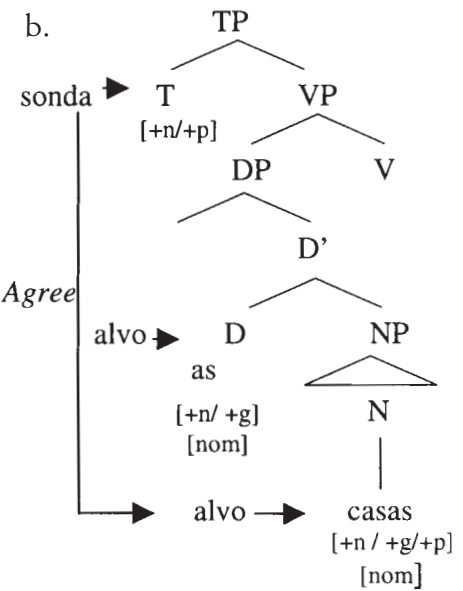

Vejamos agora como funciona a análise para os casos em que o DP é formado por determinantes (D) e adjetivos (A), como em $(20)^{18}$.

(20) a. As menina(s) bonita(s).

Em (20), o determinante tem traços de número interpretáveis e de gênero não-interpretáveis; o nome tem traços de número não-interpretáveis e de gênero interpretáveis; já para os adjetivos esses traços são nãointerpretáveis.

Vou assumir como estrutura básica para a relação sonda-alvo em DPs contendo adjetivos, a que está em (21), também assumida por Abney (1987) e Cinque (1994). Não estarei preocupada aqui em fornecer explicações para as diferentes posições que os adjetivos podem ter em relação ao nome dentro do $\mathrm{DP}^{19}$.

18 A análise pode ser estendida a casos como “ Meninas Bonitas”, bastando para tanto assumirmos que nestes casos existe um D nulo.

19 Para explicações a respeito desse assunto remeto o leitor a Abney (1987), Boff (1991), Cinque (1994), Longobardi (1994), Menuzzi (1992), Alexiadou (2001). 
(21)

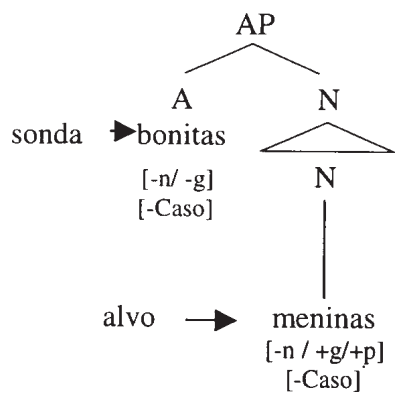

Em (21), o adjetivo (sonda) possui traços de gênero e número nãovalorados e procura um alvo para valorar esses traços. Esse alvo é o nome. No momento em que o adjetivo e o nome (N) se combinam, o adjetivo valora o seu traço de gênero, mas não consegue valorar o seu traço de número porque $\mathrm{N}$ possui traço de número não-valorado, conforme ilustrado em (22):

(22)

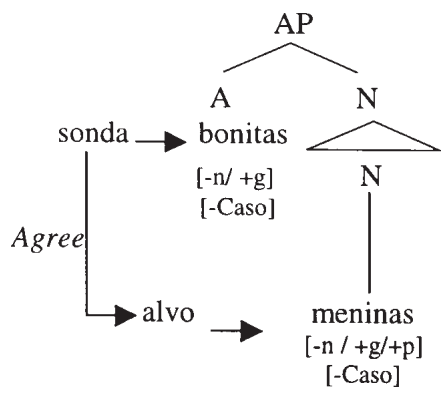

Por sua vez, em 23, D (sonda), que tem um traço de gênero para valorar, procura por um alvo capaz de valorar seu traço de gênero. Durante a procura, o primeiro alvo que $\mathrm{D}$ encontra é o adjetivo (alvo) ${ }^{20} \mathrm{e} \mathrm{D}$, que tem traço de número interpretável, valora o traço de número de $\mathrm{A}$ :

20 Estou assumindo, diferentemente de Chomsky (1999), que categorias lexicais como o adjetivo podem também funcionar como alvo. 
(23)

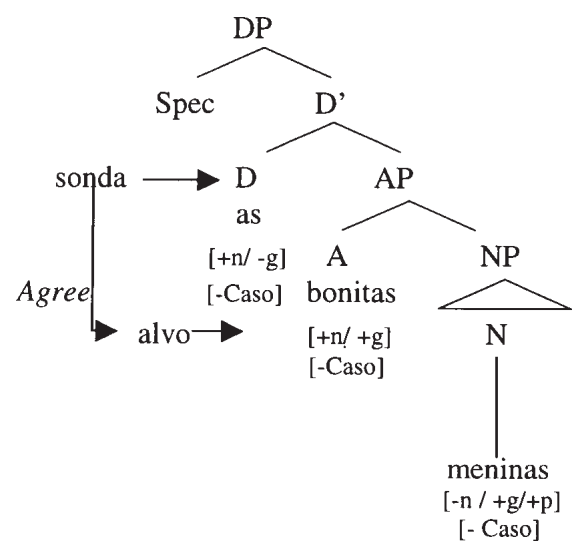

No entanto, A não pode valorar o traço de gênero de $\mathrm{D}$ porque $\mathrm{A}$ tem traço de gênero não-interpretável, por isso $\mathrm{D}$ precisa continuar procurando um alvo para valorar o seu traço de gênero. Quando D encontra N, D valora o seu traço de gênero, bem como valora o traço de número de $\mathrm{N}$, como exemplificado em (24):

(24)

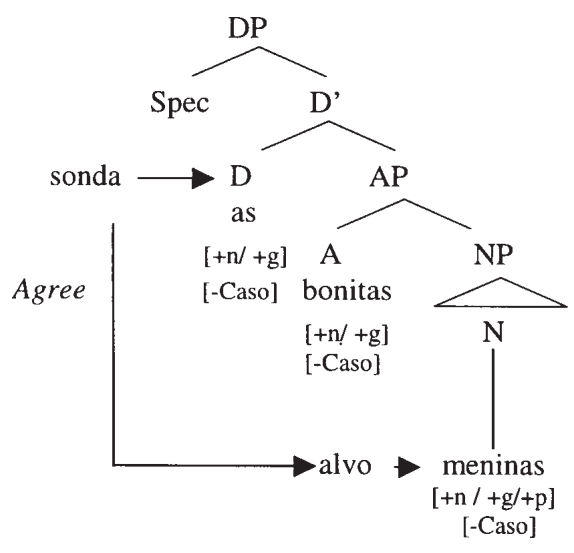

Depois de ter seus traços- $\phi$ valorados, o DP vai se combinar com uma sonda, T ou v, e valorar o seu traço de Caso. Em (25) a sonda T se combina com $\mathrm{D}$ e valora o seu traço de número e o traço de Caso de $\mathrm{D}$ : 
(25)

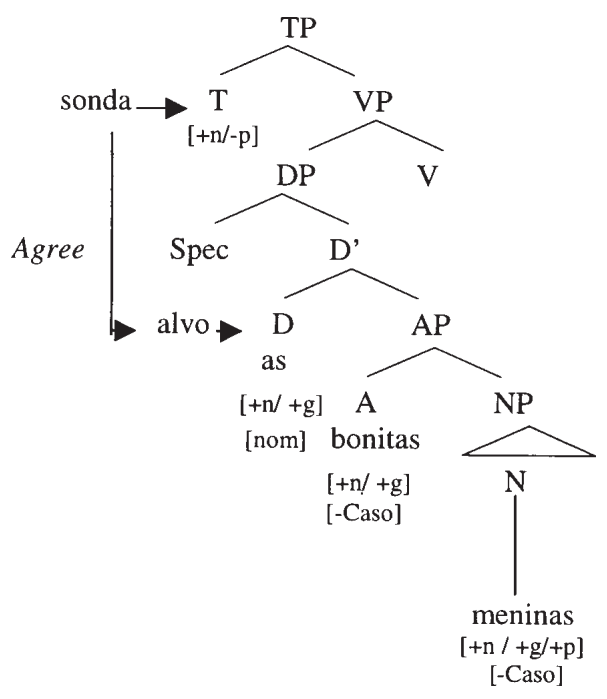

Mas a sonda (T) ainda precisa valorar o seu traço de pessoa que $\mathrm{D}$ não pôde valorar por não ter traço de pessoa. Logo, a sonda continua sua procura por um alvo para valorar o seu traço de pessoa. O próximo alvo que ela encontra é o adjetivo (A), a sonda (T), então, valora o traço de Caso de $\mathrm{A}$, mas ainda não pode valorar o seu traço de pessoa porque o adjetivo também é defectivo em traço de pessoa, conforme ilustrado em (26):

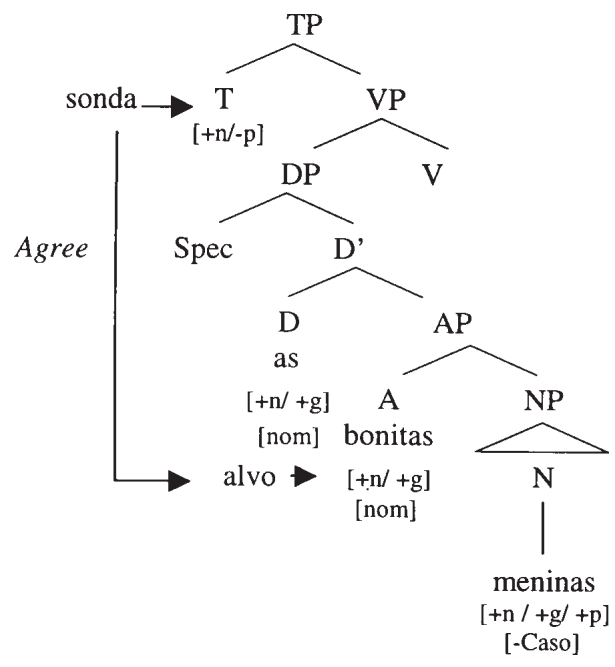


A sonda $(\mathrm{T})$ continua sua procura por um alvo e encontra o nome que possui traço de pessoa e, portanto, pode valorar o traço de pessoa de T. A sonda (T) e o alvo (N) se combinam, a sonda valora o seu traço de pessoa e valora o traço de Caso de T como (27) mostra ${ }^{21}$. Como a relação Agree do DP se dá com uma sonda T, ele terá seu Caso valorado como nominativo:

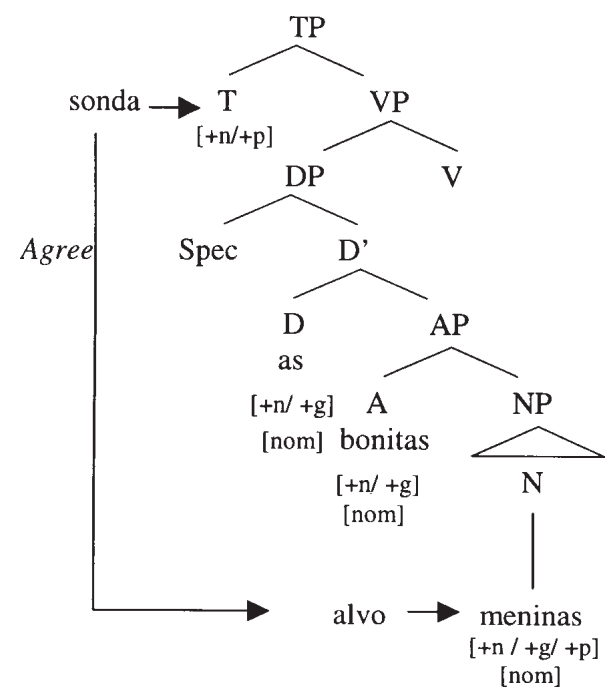

Com análise acima vimos que é possível realizar a valoração dos traços do DP usando Agree sem a necessidade de estipular nenhuma outra relação de concordância para a realização da checagem dos traços formais do DP. O sistema Agree dá conta da valoração de traços formais tanto no nível da sentença quanto no nível do $\mathrm{DP}^{22}$.

21 É importante ressaltar que D e A não induzem efeito de minimalidade para a combinação sonda $(\mathrm{T})$ e alvo $(\mathrm{N})$ porque eles são defectivos em traço de pessoa.

22 Gostaria de acrescentar que se a minha análise estiver no caminho certo, o DP não pode ser uma fase forte. Considerando a Phase Impenetrability Condition de Chomsky (1999), se o DP fosse uma fase forte, quando a derivação chegasse ao vP, o $\mathrm{N}$ teria ser mandado para o componente fonológico e não seria possível para $\mathrm{N}$ entrar em relação de Agree com v e receber Caso acusativo. 


\section{Considerações Finais}

Este trabalho tentou mostrar que é possível realizar a checagem de traços dentro do DP usando o sistema de checagem Agree de Chomsky (1999; 2001) sem a necessidade de propor nenhum outro mecanismo para tanto.

Foi proposto que primeiro ocorre a valoração dos traços- $\phi$ dos concordantes do DP e que o traço de Caso do DP é valorado quando ele entra em relação de concordância com uma sonda. A valoração dos traços dentro do DP acontece, então, da mesma forma que acontece a valoração de traços em construções participiais (Chomsky, 1999), diferindo no que diz respeito ao uso de etapas que assumo como sendo uma conseqüência da análise aqui proposta. Deste modo, a análise proposta para a valoração dos traços do DP provê evidências para a proposta de valoração dos traços em construções participiais de Chomsky (1999).

E-mail: tel2111@yahoo.com.br

Recebido em abril de 2003

Aprovado em novembro de 2003

\section{REFERÊNCIAS BibliográficAs:}

Abney, Steven. 1987. The English Noun Phrase in Its Sentential Aspect. Ph.D. diss., MIT.

Alexiadou, Artemis. 2001. Adjective Syntax and Noun Raising: word order asymmetries in the DP as result of adjective distribution. Studia Linguistica, 55/3: 217-258.

Boff, Alvana Maria. 1991. A Posição dos Adjetivos no Interior do Sintagma Nominal: Perspectivas Sincrônica e Diacrônica. Dissertação de Mestrado, UNICAMP.

Carstens, Vicki. 2000. Concord in Minimalist Theory. Linguistic Inquiry, 31/2:319-335

Chomsky, Noam. .1995. The Minimalist Program. Cambridge, Mass.: Mit Press

1998. Minimalist Inquiries: The Framework. MIT Occasional Papers in Linguistic, 15.Cambridge, Mass.: MIT Working Papers in Liguistics. .1999. Derivation by Phases. Ms. 
.2001. Beyond Explanatory Adequacy. Ms.

CINQUE, Guglielmo. 1994. On The Evidence for partial N-movement in the Romance DP. In: Paths Towards Universal Grammar: Studies in honor of Richard S. Kayne, ed. Guglielmo Cinque, Jan Koster, Jean Ives Pollock, Luigi Rizzi, and Raffaella Zanuttini. Washington, D.C.: Georgetown University Press: 85-110.

Lobato, Lúcia 1994. A concordância Nominal no Português do Brasil à Luz da Teoria de Princípios-e-Parâmetros e da Sociolingüística Variacionista. D.E.L.TA., 10: 173-212.

Longobardi, Giuseppe. 1994. Reference and Proper Names: a theory of movement in syntax and LF. Linguistic Inquiry, 25: 609-665.

Menuzzi, Sérgio. 1992. Sobre a Modificação Adjetival do Português: Uma Teoria de Projeção dos Adjetivos. Tese de Doutorado, UNICAMP.

Nunes, Jairo Morais. 1994a. Concordância de Particípio em Lituano. Letras de Hoje, 29/2: 59-83.

.1994b. Participle Constructions in Lithuanian. Dissertação de Mestrado, University of Maryland, College Park.

Olsen, Suzan. 1989. AGR(eement) in the German Noun Phrase. In: BHAYY, CHR., LÖBEL, E. \& SCHMIDT, C. (eds.). Syntactic Phrase Structure Phenomena in Noun Phrase E Sentences. Amsterdam: John Benjamins: 39-49.

Scherre, Maria Marta Pereira. 1988. Reanálise da Concordância Nominal em Português. Tese de Doutorado. UFRJ. 